\title{
The success rate and associate factors of vaginal birth after cesarean section at Tu Du Hospital in Vietnam
}

\begin{abstract}
Short Background: The cesarean section rate is $47 \%$ at $\mathrm{Tu}$ Du hospital, evaluating the level of likelihood that trial of labor after cesarean section (TOLAC) and factors associated with successful VBAC would be need to be analyzed.

Objective: To identify the success rate of vaginal birth after cesarean section (VBAC) and factors associated with vaginal delivery in who previously had a cesarean section at Tu Du hospital in Vietnam.

Methods: A prospective observational study was conducted on women who were $\geq 28$ weeks pregnant and previously had a cesarean section. Data was collected from November 2013 to March 2014 from participants that were admitted to the delivery department at Tu Du hospital.

Results: 399 pregnant women who had one previous cesarean section were enrolled in the study. The success rate of VBAC was $54.14 \%$ [95\%CI: 49.11-59.10]. The variables that affected the success rate of VBAC were: Bishop Score on admission $\geq 7$ $\left(\mathrm{OR}^{*}=4.00\right)$ compared to Bishop Score on admission $<5$, labor induction $\left(\mathrm{OR}^{*}=0.18\right)$ compared to spontaneous labor, amniotic fluid stained with meconium $\left(\mathrm{OR}^{*}=0.19\right)$. The incidence of uterine rupture was $1 \%$. There was no significant difference in blood loss between vaginal delivery and cesarean delivery cases.

Conclusion: The success rate of VBAC was $54.14 \%$. The uterine rupture and postpartum hemorrhage rate were comparable to other studies on VBAC. If there were no contraindications and participants had favorable factors, women with previous cesarean section were given the opportunity to attempt vaginal birth.
\end{abstract}

Keywords: vaginal birth after cesarean section, labor, postpartum hemorrhage, TOLAC
Volume 4 Issue 3 - 2018

\section{Tuan Vo Minh, Hien Nguyen Phuoc}

Department of Obstetrics \& Gynecology, University of Medicine and Pharmacy, Vietnam

\begin{abstract}
Correspondence: Tuan Vo Minh, Department of Obstetrics \& Gynecology, University of Medicine and Pharmacy, Ho Chi Minh City, 217 Hong Bang D5, HCMC, Vietnam, Tel 848385 584II, Email Drvo_obgyn@yahoo.com.vn
\end{abstract}

Received: May 24, 2017| Published: May 07, 2018

\section{Introduction}

Cesarean section rate has been steadily increasing in most countries. Between 1970 and 2007, ${ }^{1}$ the cesarean delivery rate in United State increased from $5 \%$ to $31 \%$. Consequently, the proportion of pregnant women with previous cesarean delivery increased. Managing high risk pregnancy continues to be a challenge to all Obstetricians.

The most appropriate mode of subsequent delivery of women with prior caesarean birth continues to be a subject of intense research and debate in contemporary obstetric practice. This controversy remains a major public health issue because the two options for delivery: planned elective repeat caesarean or planned vaginal birth in a subsequent pregnancy for these cohort of woman with a previous caesarean birth are associated with both significant maternal and perinatal benefits and risks. Vaginal birth after caesarean delivery (VBAC) has long been proposed as a viable measure to reduce overall caesarean delivery rates in both developed and developing countries. It has been found to be safe with careful patient selection and good management of labour with success rates ranging between $60 \%$ and $80 \%{ }^{2}$

At $\mathrm{Tu} \mathrm{Du}$ hospital, the cesarean section rate is $47 \%$. The rate of placenta previa, placenta increta and ectopic pregnancy at cesarean scar also increased dramatically. Therefore, we are always encouraged trial of labor after cesarean section if no contraindication exist. Evaluating the level of likelihood that trial of labor after cesarean section (TOLAC) and factors associated with successful VBAC would be need to be analyzed. Therefore, we performed the study to determine the success rate of vaginal birth after cesarean section and the factors associated with the success rates.

\section{Study objectives}

a. To identify the success of vaginal birth rate of pregnant women who previously had a cesarean section from November 2013 to March 2014 at Tu Du hospital.

b. To examine the factors that are associated with a successful vaginal delivery after a cesarean section from November 2013 to March 2014at Tu Du hospital.

\section{Methods}

\section{Study population}

Pregnant women who had one previous cesarean section who were admitted to delivery department and indicated for trial of labor at TuDu hospital from November 2013 through March 2014. 
Inclusion criteria:

Low transverse previous incision in uterus

Gestational age $\geq 28$ weeks

Singleton pregnancy

Cephalic presentation

Obtaining agreement for enrolling study

\section{Exclusion criteria:}

Stillbirth

Congenital malformations

Previous multiple cesarean section ( $\geq 2$ times)

\section{Study design:}

Prospective observation study

Study time: November 2013 to March 2014

Study place: Delivery department at Tu Du hospital

\section{Sample size:}

$$
\mathrm{N}=\mathrm{Z} 21-\alpha / 2 \times \mathrm{P}(1-\mathrm{P}) / \mathrm{d}^{2}
$$

P: Variation from $40 \%$ to $80 \%$ from the previous studies. ${ }^{3}$ Set $\mathrm{P}=0.5$ for maximizing sampling power; $\alpha=0.05 ; \mathrm{d}=0.05 \Rightarrow$ Sample size: 386

Sampling method: Enroll all participants that qualified during study period.

\section{Study procedure:}

Step 1: Screening pregnant women who previously had cesarean section admitted to delivery department and indicated for vaginal birth by senior doctors.

Step 2: Enrolling women who qualified and obtaining their consent forms.

Step 3: Interviewing, observing, and filling out questionnaires.

Steps 4: Following up with participants as an observer.

Steps 5: Recording results and data post-delivery and on the fourth day of post-operation.

Data analysis: We calculated crude and adjusted odds ratios (with 95 percent confidence intervals) as measures of the association between VBAC use and relative variables. Logistic regression was used to control for other factors simultaneously.

\section{Ethical considerations}

This was observational study only. Moreover, the institutional review boards of UMP and the participating hospitals approved the study (166/ĐHYD-HĐ 2013 and 397/QĐ - BVTD 2013); written informed consent was obtained from all enrolled women.

\section{Results}

From November 2013 to March 2014, there were 17,083 women who were more than 28 weeks pregnant admitted to delivery department at $\mathrm{Tu} \mathrm{Du}$ hospital. Among them, 2,634 women had previously had cesarean section (15.4\%). After screening, 399 women were indicated for trial of labor after cesarean section (TOLAC). All of them qualified and also finished the study.

\section{Characteristics of study subjects (Table I)}

In our study, there were 7 cases that had remaining indications of previous cesarean section: pelvic contraction. All seven cases were preterm births. Among them, 5 cases were indicated for TOLAC. One case indicated for cesarean section due to cephalopelvic disproportion because of pelvic contraction. There were no X-Ray pelvimetry, IUDR, or SGA. Their labor progressed to active stage so we proceeded with TOLAC. Another case that indicated for cesarean was a midpelvic contraction on X-Ray pelvimetry. She was indicated for a repeat cesarean section. However, the labor progress quickly to second stage. Both of them had successful vaginal delivery without complication.

Table I Subject's characteristics

\begin{tabular}{lll}
\hline Characteristics & Number of cases (N=399) & Percentage (\%) \\
\hline Maternal age & & \\
$\leq 25$ & 33 & 8.27 \\
$26-35$ & 290 & 72.68 \\
$>35$ & 76 & 19.05 \\
BMI score & & \\
Normal & 257 & 64.41 \\
Low weight & 55 & 13.78 \\
Over weight & 87 & 21.8 \\
Parity & & \\
One time & 327 & 81.95 \\
2 times or more & 72 & 18.05 \\
Vaginal birth before C section & \\
No & 358 & 89.72 \\
Yes & 41 & 10.28 \\
History of VBAC & & \\
No & 375 & 93.98 \\
Yes & 24 & 6.02 \\
Interconnectional period & \\
$\leq 24$ months & 22 & 5.51 \\
$>24$ months & 377 & 94.49 \\
Gestational age & & \\
28 weeks-36 & 50 & \\
weeks \& days & & \\
37 weeks-40 & 304 & \\
weeks & & \\
$>40$ weeks & 45 & \\
Onset of labor & & \\
Spontaneous & 302 & \\
\hline
\end{tabular}


Table continued

\begin{tabular}{lcl} 
Characteristics & Number of cases $\mathbf{( N = 3 9 9 )}$ & Percentage (\%) \\
\hline $\begin{array}{l}\text { Induction of } \\
\text { labor }\end{array}$ & 97 & 24.31 \\
BISHOP score at admission & \\
$<5$ & 97 & 24.81 \\
$5-6$ & 186 & 47.57 \\
$\geq 7$ & 108 & 27.62 \\
Late hospital admission & \\
No & 382 & 95.74 \\
Yes & 17 & 4.26 \\
Augmentation & & 100 \\
No & 399 & 0 \\
Yes & 0 & 100 \\
Epidural Analgesia & 399 & 0 \\
No & 0 & \\
Yes & & \\
\hline
\end{tabular}

\section{Result of trial of labor after cesarean section (Table 2)}

Table 2 Characteristic of outcome trial of labor after cesarean section

\begin{tabular}{|c|c|c|}
\hline Characteristic & $\begin{array}{l}\text { Number of } \\
\text { cases }\end{array}$ & Percentage \\
\hline \multicolumn{3}{|l|}{ Mode of delivery } \\
\hline Vaginal delivery & 216 & 54.14 \\
\hline Cesarean delivery & 183 & 45.86 \\
\hline \multicolumn{3}{|l|}{ Mode of vaginal delivery } \\
\hline Spontaneous delivery & 164 & 75.93 \\
\hline Instrument delivery & 52 & 24.07 \\
\hline \multicolumn{3}{|c|}{ Current indication of cesarean delivery } \\
\hline Failed progress of labor & 92 & 50.27 \\
\hline Cephalopelvic disproportion & 10 & 5.46 \\
\hline Fetal distress & 22 & 12.02 \\
\hline Hypertonic uterine dysfunction & 17 & 9.29 \\
\hline Scar tenderness & 9 & 4.92 \\
\hline $\begin{array}{l}\text { Cesarean scar-membrane } \\
\text { rupture }\end{array}$ & 31 & 16.94 \\
\hline $\begin{array}{l}\text { Cesarean scar - presence of } \\
\text { meconium }\end{array}$ & 1 & 0.55 \\
\hline Uterine rupture & 1 & 0.55 \\
\hline \multicolumn{3}{|l|}{ Time of current cesarean delivery } \\
\hline Latent first stage & 78 & 42.62 \\
\hline Active first stage & 97 & 53.01 \\
\hline Second stage & 8 & 4.37 \\
\hline
\end{tabular}

There were 216 cases of vaginal delivery and 183 cases of cesarean delivery. Thus, the success rate of vaginal delivery after cesarean section was $54.14 \%$ [95\%CI: 49.11-59.10].

\section{Characteristics of labor (Table 3) (Table 4)}

Table 3 Characteristics of labor in vaginal birth group

\begin{tabular}{lll}
\hline Characteristics & Number of cases & Mean (Minute) \\
\hline First stage & & \\
Latent stage & 128 & $413.64 \pm 262.03$ \\
Active stage & 208 & $145.29 \pm 140.80$ \\
Second stage & & \\
Second stage & 216 & $14.73 \pm 10.70$ \\
\hline
\end{tabular}

Mean latent stage duration in vaginal delivery was $413.64 \pm 262.03$ minutes (\#6.89 hrs). It was similar to multiparas Friedman curve. Mean active stage duration was 2.4 hours which was similar to multiparas Friedman curve either.

Table 4 Characteristic of labor in repeat C-section cases

\begin{tabular}{llc}
\hline Characteristics & Number of cases & Mean (Minute) \\
First stage & & \\
Latent stage & 68 & $447.84 \pm 214.18$ \\
Active stage & 8 & $129.38 \pm 86.79$ \\
\hline
\end{tabular}

Among repeat $\mathrm{C}$-section group, 68 cases progressed to latent labor with a mean duration of $447.84 \pm 214.18$ minutes $(7.46 \mathrm{hrs})$. It was much longer compared to multiparas Friedman curve. Mean active stage duration was 2.15 which was similar to multiparas Friedman curve.

Second stage of labor was measured from cervical complete dilatation until the delivery. The median duration was approximately 50 minutes for nulliparous and about 20 minutes for multiparas. In our study, all women had a mean second stage duration of $14.73 \pm 10.70$ minutes. Due to hospital policies, we were asked to apply assistant delivery for previous $\mathrm{C}$ section cases. This accounted for the shortened delivery time compared to normal vaginal delivery.

\section{The association between mode of delivery and factors (Table 5)}

Table $\mathbf{5}$ The association between mode of delivery and factors

\begin{tabular}{|c|c|c|c|c|c|}
\hline Characteristics & $\begin{array}{l}\text { Vaginal } \\
\text { delivery } \\
(\mathrm{N}=\mathbf{2 1 6})\end{array}$ & $\begin{array}{l}\text { Cesarean } \\
\text { delivery } \\
(\mathbf{N}=183)\end{array}$ & OR* & $95 \% \mathrm{CI}$ & $P^{*}$ \\
\hline \multicolumn{6}{|l|}{ VBAC } \\
\hline No & $196(52.27)$ & $179(47.73)$ & Ref & \multirow{3}{*}{$\begin{array}{l}0.68- \\
10.35\end{array}$} & \multirow[b]{2}{*}{0.158} \\
\hline Yes & $20(83.33)$ & $4(45.86)$ & 2.63 & & \\
\hline \multicolumn{5}{|l|}{ Onset of labor } & \\
\hline Spontaneous & 194(64.24) & $108(35.76)$ & Ref & \multirow{3}{*}{$\begin{array}{l}0.10- \\
0.35\end{array}$} & \multirow[b]{2}{*}{0} \\
\hline $\begin{array}{l}\text { Induction of } \\
\text { labor }\end{array}$ & $22(22.68)$ & $75(77.32)$ & 0.18 & & \\
\hline \multicolumn{5}{|c|}{ BISHOP score on admission } & \\
\hline$<5$ & $33(34.02)$ & $64(65.98)$ & Ref & \multirow{3}{*}{$\begin{array}{l}1.33- \\
4.24 \\
2.04- \\
7.83\end{array}$} & \multirow[b]{2}{*}{0.003} \\
\hline $5-6$ & $101(54.30)$ & $85(45.70)$ & 2.37 & & \\
\hline$\geq 7$ & $74(68.52)$ & $34(31.48)$ & 4 & & 0 \\
\hline \multicolumn{6}{|c|}{ Status of amniotic fluid } \\
\hline Normal & $211(55.67)$ & $168(44.33)$ & Ref & & \\
\hline Meconium & $5(25)$ & $15(75.00)$ & 0.19 & $\begin{array}{l}0.06- \\
0.62\end{array}$ & 0.006 \\
\hline
\end{tabular}


A univariate analysis was done for all variables to find out the association with mode of delivery. We completed a univariate analysis for 21 pairs of variables. Then, we collected the variables which had $\mathrm{P}$ value $<0.25$ and completed a multivariate analysis. Sample size 399 had enough sample power for multivariate analysis of 11 pairs of variables. There were 3 variables which had a statistically significant association with mode of delivery on pregnant women who previously had a cesarean section.

\section{The complication during trial of labor after cesarean section}

Uterine rupture (Table 6)

Table 6 Uterine rupture

\begin{tabular}{lll}
\hline Uterine rupture & $\begin{array}{l}\text { Number of cases } \\
(\mathbf{N = 3 9 9 )}\end{array}$ & Percentage (\%) \\
\hline No & 395 & $99 \%$ \\
Yes & 4 & $1 \%$ \\
\hline
\end{tabular}

Postpartum hemorrhage (Table 7) (Table 8)

Table 7 Postpartum hemorrhage

\begin{tabular}{|c|c|c|c|c|c|}
\hline Characteristic & $\begin{array}{l}\text { Vaginal } \\
\text { delivery } \\
(\mathrm{N}=\mathbf{2 1 6})\end{array}$ & $\begin{array}{l}\text { Cesarean } \\
\text { delivery } \\
(\mathrm{N}=183)\end{array}$ & $\mathrm{OR}^{*}$ & $95 \% \mathrm{CI}$ & $P^{*}$ \\
\hline \multicolumn{6}{|c|}{ Postpartum hemorrhage } \\
\hline No & $194(89.81)$ & $181(98.91)$ & Ref & & \\
\hline Yes & $22(83.33)$ & $2(1.09)$ & 10.26 & $\begin{array}{l}2.37- \\
44.16\end{array}$ & 0.002 \\
\hline
\end{tabular}

Table 8 Blood loss after birth

\begin{tabular}{lclll}
\hline Characteristic & Mean & $\begin{array}{l}\text { Mean } \\
\text { diff }\end{array}$ & $\mathbf{9 5 \% C I}$ & $\mathbf{P}^{*}$ \\
\hline $\begin{array}{l}\text { Cesarean deli- } \\
\text { very }\end{array}$ & 237.43 & & & \\
Vaginal delivery & 261.11 & 23.68 & $231.94-268.56$ & 0.184 \\
\hline
\end{tabular}

\section{Other complications}

There was no maternal and neonatal mortality in the study. The number of Low Apgar score was not statistically significant between vaginal and cesarean delivery.

There was a case with fourth-degree lacerated that should carry out repair-episiotomy at operation room.

There was three cases lacerated uterus during cesarean delivery. There was no urinary tract and gastrointestinal injury.

There was one case of hematoma at abdominal wall after operation. We had to repeat operation. The duration of hospital stay for the case had lasted 10 days.

There was an emergency hysterectomy after vaginal birth. Right after spontaneous delivery, the patient was diagnosed with uterine rupture. While repairing uterine rupture, the patient suddenly went into cardiac arrest. A secondary uterine atony was indicated for emergency hysterectomy.

\section{Discussion}

In the study, $24.31 \%$ cases had induction of labor by transcervical catheter. TuDu hospital had allowed this method only to induce labor with previous cesarean scar. While other studies such as Puja Puri 2011 used Cerviprime cream to induce labor, ${ }^{4}$ and Dadhwal 2003 study used Oxytocin to induce labor. ${ }^{1}$ There were 8 cases admitted to the hospital late when cervical were dilated more than $8 \mathrm{~cm}$.

In Tu Du hospital, no obstetric analgesia were given fearing it would mask the scar tenderness. None of the cases used oxytocin for augmentation of labor because of the hospital policies. This characteristic was similar to Malede Birara 'study 2013.5

The success rate of vaginal delivery after cesarean section was 54.14\% [95\%CI: 49.11-59.10]. This result was similar to Malede Birara $2013^{5}$ study with success rate of $49.5 \%$ and Puja Puri 2011 study ${ }^{4}$ with success rate of $56.1 \%$. However, the study of Doshi Haresh $\mathrm{U}^{2}$ and the study of Vidyadhar B Bangal ${ }^{6}$ showed a higher success rate of $85 \%$. This difference could have resulted from the sampling size in our study which was 4 times that of Vidyadhar's study (399 compared to 100). In addition, Vidyadhar study allowed using oxytocin for augmentation of labor which increased the opportunity for vaginal delivery in prolonged labor cases due to lack of uterine contraction. Oxytocin might reduce cesarean delivery rate because of failed progress of labor. Moreover, 70\% of research subjects in Vidyadhar study had VBAC (compared 10\% in our study).

Regarding the mode of vaginal delivery, $24.1 \%$ cases had assistant deliveries (forceps or vacuums). The assistant vaginal delivery rate in our study was much higher than the general assistant vaginal delivery rate of TuDu hospital (5\%). This difference could have resulted from TuDu's policy that indicated for assistant vaginal delivery very early in second stage of the labor of pregnancies with previous $\mathrm{C}$ section. However, assistant vaginal deliveries rate in our study was similar (or lower) to Doshi Haresh U 25.99\%, ${ }^{2}$ Malede Birara ${ }^{5} 35.5 \%$, and Puja Puri $437.4 \%{ }^{4}$

Among the repeat $\mathrm{C}$-section group, $50.27 \%$ cases failed progress of labor. This rate in our study was lower than in Malede Birara's study (2013) 66\%. ${ }^{5}$ The main indication of repeat C-section in Vidyadhar's study was fetal distress $(46.67 \%),{ }^{6}$ and failed progress of labor was only $13.33 \%$. It was explained that Vidyadhar used Oxytocin to adjust uterine contraction during labor, so the rate of fetal distress increased.

The success vaginal delivery rate in cases with Bishop Score 5 to 6 on admission was 2.37 times higher as against less than 5 score (95\%CI: 1.33-4.24). The success vaginal delivery rate in cases with Bishop score $>7$ on admission was 4 times higher as compared to participants with less than 5 score (95\%CI: 2.04-7.83). This was as same as Puja Puri's study. ${ }^{4}$

Spontaneous onset of labor was found to be important factor in predicting success of VBAC. Compared to the induction labor group, spontaneous labor group had a successful vaginal delivery rate 5.5 times higher (95\%CI: $0.10-0.35)$. Presence of meconium declined chances of successful VBAC $81 \%$ (95\%CI: 0.06-0.62). Malede Birara had reported the same result in $2013 .^{5}$

Vidyadhar, ${ }^{6}$ Malede Birara ${ }^{5}$ and Doshi Haresh ${ }^{2}$ analyze factors associated with successful VBAC had reported successful vaginal 
delivery after cesarean section was a strong factor determining success. Our study data did not conclude this association. Our study resulted in only 24 women that had a successful VBAC(6\%).

Uterine rupture rate in our study was $4 \%(4 / 399)$. This was much higher than rupture rate of unscarred uterus as $1 / 20000 .{ }^{7,8}$ However, as compare to other studies on VBAC, the uterine rupture rate in our study was very similar or lower. Vidyadhar's study ${ }^{6}$ was $2 \%$; Puja Puri was $1.95 \%{ }^{4}$ The use of oxytocin during labor causes a higher uterine rupture rate.

Postpartum hemorrhage rate in vaginal delivery group was significantly higher than cesarean delivery group. This definition estimates the blood loss in excess of $500 \mathrm{~mL}$ following a vaginal birth or a loss of greater than $1000 \mathrm{~mL}$ following cesarean delivery. However, table 8 showed no statistically significant difference in blood loss between vaginal delivery cases and cesarean delivery cases $(\mathrm{P}>0.05)$.

\section{Conclusion}

Study data showed that trial of labor after cesarean section has a high successful rate and safety with careful evaluation and monitoring.

In our study, repeat cesarean section due to failed progress of labor and early membrane rupture had high proportion. We will research more about the efficiency and safety of using Oxytocin to adjust proper uterine contraction on pregnant women who previously had cesarean section.

\section{Acknowledgements}

We are indebted to the participants for making this research possible and to all physicians of delivery unit of Tu Du hospital.

\section{Conflicts of interest}

We declare that we have no conflict of interest. Tuan Vo-involved in the study design, as well as the planning, conducting, interpretation of data and editing the manuscript. Hien Nguyen - involved in sample collection, statistical analysis, interpretation of data, and drafting the manuscript.

\section{References}

1. Dadhwal V. Vaginal birth after cesarean delivery: Variables affecting outcome. JK Science. 2003;5(1):11-14.

2. Doshi Haresh U, Jain Rohit K. Prognostic factors for successful vaginal birth after cesarean section. J Obstet Gynecol India. 2010;60(6):498-502.

3. Royal. Green-top guideline no 45. RCOG Press, London; 2007.

4. Puja P, Abraham Seema GM. Vaginal birth after one previuos lower segment Caesarean section. JK Science. 2011;13(4):179-181.

5. Birara M, Gebrehiwot Y. Factor associated with success of vaginal birth after one cesarean section at three teaching hospital in Addis Ababa, Ethiopia: a case control study. BMC Pregnancy Childbirth. 2013;13:31.

6. Bangal VB, Giri PA, Shinde KK, et al. Vaginal Birth after Cesarean Section. N Am J Med Sci. 2013;5(2):140-144.

7. Zwart JJ, Richters JM, Ory F, et al. Uterine rupture in The Netherlands: a nationwide population-based cohort study. BJOG. 2009;116(8):1069-1074.

8. Hamilton BE. Birth: Preliminary data for 2007. National Vital Statistics Reports. 2009;57(12):12-18. 